\title{
A Simple Model for Flux Weakening in Surface PM Synchronous Machines Using Back-to-Back Thyristors
}

Ayman M. EL-Refaie, Student Member, IEEE, Donald W. Novotny, Fellow, IEEE, and Thomas M. Jahns, Fellow, IEEE

\begin{abstract}
Flux weakening in surface permanent magnet (PM) synchronous machines is revisited in this letter. The condition for achieving infinite constant power speed ratio (CPSR) is explained from the machine equivalent circuit and phasor diagram point of view. Back-to-back thyristors, or triac, switches feeding the three phases of a surface PM synchronous machine will be shown to be equivalent to a simple series reactance with respect to fundamental component behavior. Using such switches is equivalent to adding a series inductance to the machine. This additional inductance helps extend the CPSR of surface PM synchronous machines. This is significant because extending the CPSR of surface PM machines is usually a challenging task due to the presence of low-permeability surface magnets and the resulting low machine inductance.
\end{abstract}

Index Terms-Flux weakening, permanent magnet, synchronous machines, thyristors, triacs.

\section{INTRODUCTION}

$\mathbf{F}$ LUX WEAKENING allows a machine to operate above base speed in the constant-power, high-speed region when there is a fixed inverter voltage and current. Below base speed, all of the stator current can be used to produce torque (constant torque region). Above base speed, part of the stator current must be used to oppose the permanent magnet flux while the remaining portion is used to produce torque.

Without flux weakening, a machine must be designed to produce rated torque over the entire speed range. Disadvantages of this approach include 1) required oversizing of the inverter, and 2) low machine-phase inductance. Low inductance places higher demands on the power device switching requirements and creates high short-circuit currents that can destroy the windings and/or inverter. The two high-speed operation possibilities are shown in Fig. 1.

Several authors have addressed flux weakening in PM machines, [1]-[4], and [5]. In [4], the main design criterion for optimal flux weakening has been presented. The purpose of this criterion is to make the magnet flux linkage equal to the $d$-axis stator flux linkage (valid for both smooth air gap and salient-pole machines)

$$
\Psi_{m}=L_{d} I_{R}
$$

Manuscript received March 12, 2004; revised June 4, 2004. Recommended by Associate Editor P. L. Chapman.

The authors are with the Department of Electrical and Computer Engineering, University of Wisconsin, Madison, WI 53706 USA (e-mail: elrefaie@cae.wisc.edu; novotny@engr.wisc.edu; jahns@engr.wisc.edu).

Digital Object Identifier 10.1109/LPEL.2004.832635

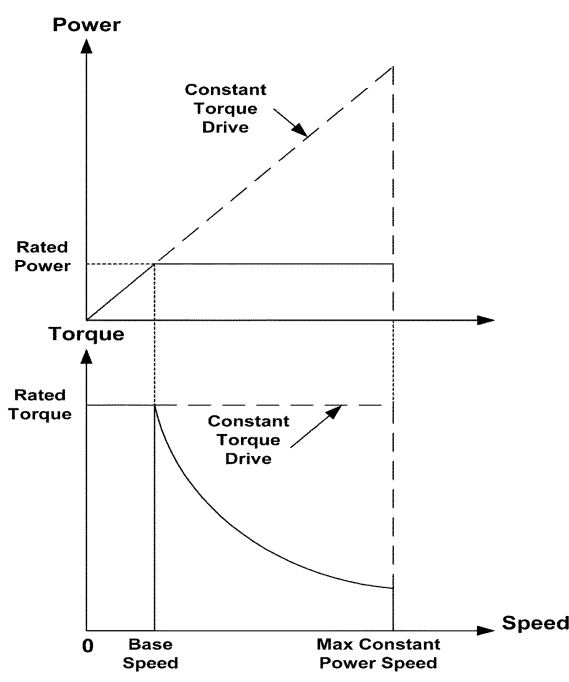

Fig. 1. Flux weakening and constant torque operation.

where $\Psi_{m}$ is the magnet flux linkage, $L_{d}$ is the $d$-axis inductance (which is the same as the $q$-axis inductance for surface PM machines), and $I_{R}$ is the rated or maximum current of the converter.

The major challenge in surface PM machines is the low phase inductance resulting from the presence of permanent magnets in the air gap; these significantly increase the effective air gap length. There are two main types of surface PM synchronous machines. The first is the brushless dc machine. Here, the back emf is trapezoidal and there are a variety of current waveforms that can be used to feed the machine in order to minimize the torque ripple. The second type is the surface PM ac machine. In this case, the back emf is sinusoidal and the machine is fed by sinusoidal currents. The focus of this letter is on the second type where we can use the concept of phasor diagram.

The challenges associated with flux weakening for a brushless dc machines have been addressed by several authors [6], [7]. Several of these flux weakening methods are based on classical phase-advance techniques [6], [7]. There are some limitations on the effectiveness of these methods, principally due to the low inductance of the machine.

An improved method to extend the constant power speed range of the brushless dc motor using dual-mode inverter control has been proposed [9] and verified experimentally [10]. This method combines both the phase-advance technique and back-to-back thyristors in each phase. The reason or justification for using back-to-back thyristors, as described 
by the authors, is that the thyristors block the conduction of the anti-parallel diodes. This eliminates the regenerative torque component produced by the diodes' conduction, hence increasing the net torque and power produced by the machine.

In this letter our goal is to show that by introducing a fundamental component approximation, the use of back-to-back thyristors to control a surface PM ac synchronous machine is equivalent to adding an extra inductance in each machine phase that is useful for extending the CPSR.

\section{PHASOR DiAgram}

We illustrate the validity of condition (1) for optimal or ideal flux weakening by using a phasor diagram. We will assume that the voltage drop across the machine resistance is small and can be neglected. Below and up to base speed, we assume the phase current is aligned with the back emf and hence all the current contributes to torque production. This case is shown in Fig. 2.

As the speed increases above base speed, the current is advanced relative to the $q$-axis. In this case the $q$-axis current component contributes to the torque production while the $d$-axis current generates $d$-axis armature flux that opposes the magnet flux. The net result is that the air gap flux is reduced so that the phase voltage stays within the limits of the available converter voltage. This is flux weakening by definition. This case is shown in Fig. 3.

As the speed keeps increasing, both the back emf and the voltage drop across the inductance increase proportionally. If condition (1) is not satisfied with the magnet flux-to-inductance value exceeding the converter-rated current, the back emf and the voltage drop across the inductance will both grow at the same rate until at a certain speed voltages $\mathrm{V}, \mathrm{E}$, and $\mathrm{I} \omega \mathrm{L}$ are in phase, as shown in Fig. 4. Beyond this speed, the machine is unable to produce motoring torque and thus can no longer be operated as a motor.

If condition (1) is exactly satisfied, the back emf, the terminal voltage, and the voltage drop across the inductance form an isosceles triangle and will grow at the same rate. Here, there is no theoretical limit on the maximum speed at which the machine can be operated, as shown in Fig. 5. The difference between the inductance voltage drop and the back emf is what really controls the maximum allowable speed. The closer this ratio is to unity, the higher the maximum allowable speed and vice versa.

The variables used in the previous phasor diagrams are defined as follows: $V_{\mathrm{ph}}$ is the phase voltage [Volts], $I_{\mathrm{ph}}$ is the phase current [Amps], $E$ is the phase back emf [Volts], $L$ is the machine phase equivalent inductance [Henries], $\omega$ is the electrical angular velocity $[\mathrm{rad} / \mathrm{sec}], \Phi_{\mathrm{mag}}$ is the flux produced by the magnets [Webers], $\Phi_{\text {arm }}$ is the flux produced by the armature current [Webers], and $\Phi_{\text {gap }}$ is the net air gap flux [Webers].

\section{EQUivalent CIRCUIT}

It has been shown in [11], [12] that a simple series reactance model can be used to represent the fundamental component behavior of back-to-back thyristors or triacs feeding an induction machine. This model was based on the assumption, which we are also using, that the resistance voltage drop can be neglected. The goal of this paper is to show that using back-to-back

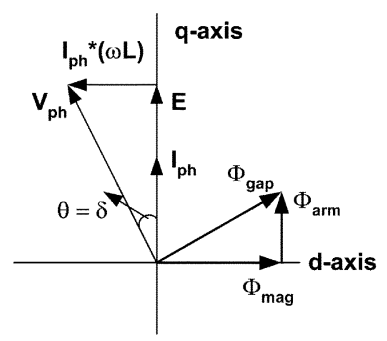

Fig. 2. Operation below base speed.

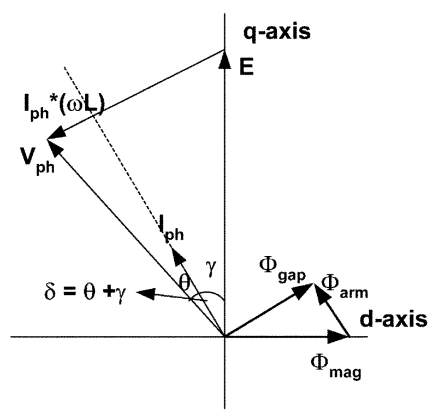

Fig. 3. Operation above base speed.

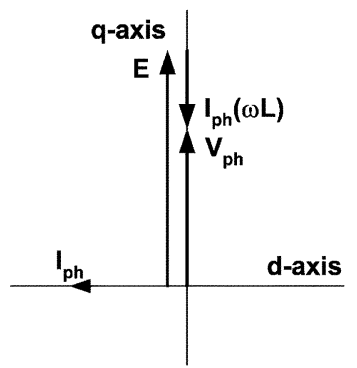

Fig. 4. Non-ideal flux weakening operation limit.
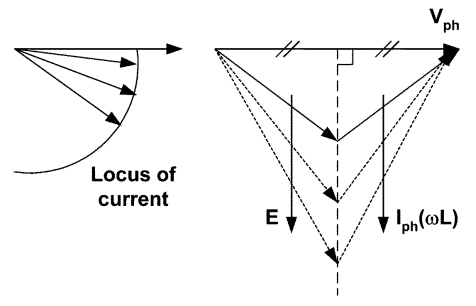

Fig. 5. Ideal flux weakening case.

thyristors or triacs to feed a surface PM synchronous machine is equivalent to adding an extra inductance in series with each machine phase for the fundamental component. This helps improve the flux weakening capabilities of the machine, as mentioned in the previous section. The equivalent circuit of the back-to-back thyristors feeding the machine is shown in Fig. 6.

The analysis will focus on phase A. The same procedure is valid for phases $B$ and $C$ with all the voltages and currents shifted by \pm 120 elec. degrees assuming a symmetrical threephase system. It is assumed that the machine is configured as a floating wye connection. The phase voltage $V_{a}$ can be written as

$$
V_{a}=V_{\mathrm{th} a}+V_{n}+E_{a}+V_{L}
$$




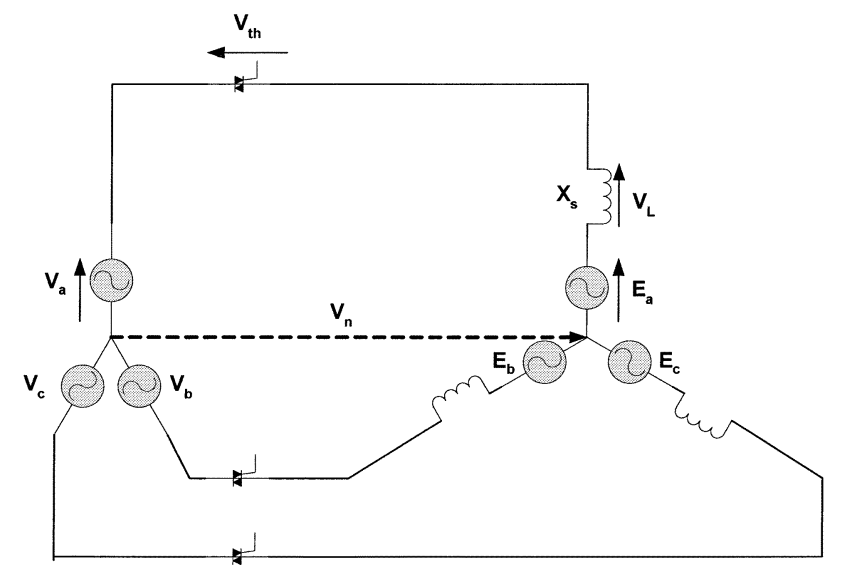

Fig. 6. Equivalent circuit of the system.

where $V_{a}$ is the phase A voltage, $V_{\mathrm{th} a}$ is the voltage drop across the thyristors in phase A, $V_{n}$ is the neutral point voltage, $E_{a}$ is the back emf of phase $\mathrm{A}$, and $V_{L}$ is the inductance voltage drop. Adding the corresponding voltage equations of the three phases leads to

$$
V_{\mathrm{th} a}+V_{\mathrm{th} b}+V_{\mathrm{th} c}=-3 V_{n}
$$

During the nonconduction period of phase A, phases B, and C are conducting

$$
\begin{aligned}
& V_{\operatorname{th} a}=-3 V_{n} \\
& V_{\operatorname{th} a}+V_{n}+E_{a}=V_{a} \\
& \frac{2}{3} V_{\operatorname{th} a}+E_{a}=V_{a} \\
& V_{\operatorname{th} a}=\frac{3}{2}\left(V_{a}-E_{a}\right) .
\end{aligned}
$$

The difference between the phase A source voltage and back emf amplitudes will be assigned its own variable $V^{\prime}$, defined as follows

$$
V_{a}-E_{a}=V^{\prime} .
$$

Since $V_{a}$ and $E_{a}$ are cosine functions phase shifted by the torque angle $\delta, V^{\prime}$ is also a cosine function and we will choose it as the new reference

$$
V^{\prime}=V_{\max }^{\prime} \cos (\omega t)
$$

so that, using (7)

$$
V_{\mathrm{th} a}=\frac{3}{2} V^{\prime}=\frac{3}{2} V_{\max }^{\prime} \cos (\omega t) .
$$

The magnitude of the fundamental component of the thyristor voltage $V_{1 \text { th } a}$ can be calculated as follows:

$$
\left|V_{1 \text { th } a}\right|=\frac{4}{\pi} \frac{3}{2} \int_{0}^{\frac{\psi b}{2}} V_{\max }^{\prime} \cos ^{2}(\omega t) d \omega t
$$

where $\psi$ is the hold-off angle of the thyristor.
This expression can be evaluated, leading to

$$
\begin{aligned}
\therefore\left|V_{\text {1h } a}\right| & \left.=\frac{1}{\pi} \frac{3}{2} V_{\max }^{\prime}[\psi+\sin (\psi)]\right] \\
V_{1 \text { th } a} & =\left|V_{1 \text { th } a}\right| \cos (\omega t) .
\end{aligned}
$$

The fundamental component of the inductance voltage drop $V_{1 L}$ can be calculated as follows

$$
V_{1 L}=V_{a}-V_{1 \operatorname{th} a}-E_{a}=V^{\prime}-V_{1 \operatorname{th} a}
$$

which, using (9), leads to

$$
\left.\therefore V_{1 L}=V_{\max }^{\prime}\left[1-\frac{1}{\pi} \frac{3}{2}[\psi+\sin (\psi)]\right]\right] \cos (\omega t) .
$$

The fundamental component of the inductor current can next be calculated as follows

$$
\begin{aligned}
I_{1 L} & \left.=\frac{V_{\max }^{\prime}}{\omega L}\left[1-\frac{1}{\pi} \frac{3}{2}[\psi+\sin (\psi)]\right]\right] \sin (\omega t) \\
\therefore I_{1 L} & =I_{1 L \max } \sin (\omega t) .
\end{aligned}
$$

Using the expressions for the fundamental component thyristor voltage and current in (15) and (16), respectively, the fundamental component equivalent reactance of the thyristor $X_{\mathrm{th}}$ is derived as

$$
X_{\text {th }}=\left|\frac{V_{1 \text { th } a}}{I_{1 L}}\right|=\omega L \frac{\left.\frac{1}{\pi} \frac{3}{2}[\psi+\sin (\psi)]\right]}{\left.\left[1-\frac{1}{\pi} \frac{3}{2}[\psi+\sin (\psi)]\right]\right]} .
$$

This equation for the thyristor fundamental equivalent reactance can be expressed as

$$
X_{\mathrm{th}}=\omega L * f(\psi)
$$

where $f(\psi)$ can be considered as a reactance factor that is a function of the hold-off angle $\psi$,

$$
f(\psi)=\frac{\left.\frac{1}{\pi} \frac{3}{2}[\psi+\sin (\psi)]\right]}{\left.\left[1-\frac{1}{\pi} \frac{3}{2}[\psi+\sin (\psi)]\right]\right]} .
$$

It can be seen from (18) that if the voltage drop across the resistance is neglected, the fundamental behavior of the back-toback thyristors can be represented by an equivalent series reactance. The value of this equivalent reactance is a function of the hold-off angle of the thyristors. Based on the previous discussion, this added reactance will improve the flux weakening capability of the machine. Experimental confirmation of the validity of improved CPSR using back-to-back thyristors is contained in [9] and [10].

Fig. 7 shows the variation of the reactance factor as a function of the hold-off angle. Another interesting point of view to explain the effect of the back-to-back thyristors is shown in Fig. 8. Since the machine inductance is constant, if the equivalent inductance of the thyristors is used to satisfy condition (1), we can see that the locus of the machine input voltage at different speeds is a vertical line. Based on this perspective, using these thyristors is equivalent to increasing the available voltage at the machine terminals for the same supply or source voltage. Since the required additional inductance is fixed for a given machine, a 


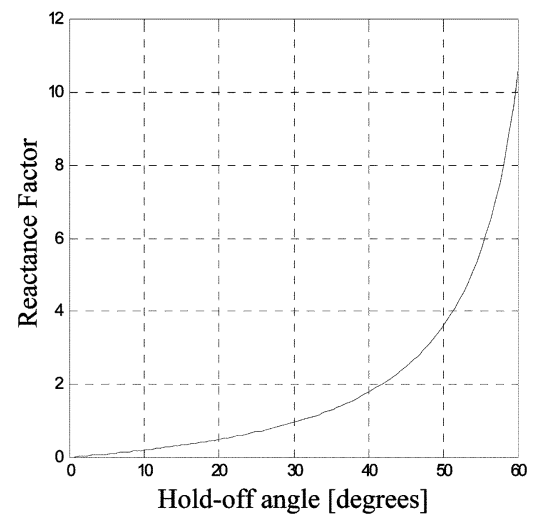

Fig. 7. Reactance factor as a function of hold-off angle.

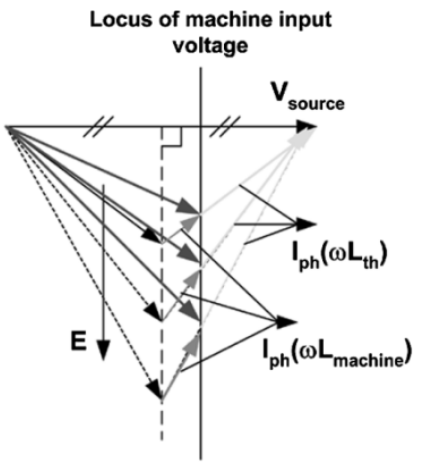

Fig. 8. Effect of the thyristor-based equivalent inductance on the machine phasor diagram for optimal flux weakening.

fixed value of hold-off angle $\psi$ is all that is required to attain constant-power operation. The same analysis can be performed in terms of $\mathrm{d}-\mathrm{q}$ equivalent circuits using the following basic equations:

$$
\begin{aligned}
& V_{q}=E+I_{d} \omega L \\
& V_{d}=-I_{q} \omega L
\end{aligned}
$$

where

$$
\begin{aligned}
& V_{\mathrm{ph}}=\sqrt{V_{q}^{2}+V_{d}^{2}} \\
& I_{\mathrm{ph}}=\sqrt{I_{q}^{2}+I_{d}^{2}} .
\end{aligned}
$$

\section{CONCLUSION}

The preceding derivation has provided a convenient way of understanding and modeling the roles of back-to-back thyristors in series with the three machine phases for extending the machine's constant power speed ratio. This analysis has shown that the thyristors serve as a convenient means for electronically increasing the value of the machine's effective phase inductance, with a scaling factor that increases monotonically with the thryristor hold-off angle. As a result, the value of the effective machine inductance for a surface magnet ac motor can be increased sufficiently to meet the conditions for optimal flux weakening determined by (1). However, the impact of the resulting harmonics introduced by the thyristor switching on other machine operating characteristics such as efficiency have not been considered in this analysis. The bulkiness of the thyristors might be another practical issue preventing the widespread use of thyristors for flux-weakening applications. The maximum CPSR achieved using this technique is 6:1, as reported in [10]. The limiting quantity is the forward blocking voltage of the thyristors.

\section{REFERENCES}

[1] T. Sebastian and G. R. Slemon, "Operating limits of inverter-driven permanent magnet motor drives," IEEE Trans. Ind. Applicat., vol. 23, pp. 327-333, Mar.-Apr. 1987.

[2] T. M. Jahns, "Flux-weakening regime operation of an interior permanent magnet synchronous motor drive," IEEE Trans. Ind. Applicat., vol. 23, pp. 681-689, July-Aug. 1987.

[3] B. Sneyers, D. W. Novotny, and T. A. Lipo, "Field weakening in buried permanent magnet Ac motor drives," IEEE Trans. Ind. Applicat., vol. 21, pp. 398-407, Mar--Apr. 1985.

[4] R. F. Schiferl and T. A. Lipo, "Power capability of salient pole permanent magnet synchronous motor in variable speed drive applications," IEEE Trans. Ind. Applicat., vol. 26, pp. 115-123, Jan.-Feb. 1990.

[5] W. Soong, "Design and Modeling of Axially-Laminated Interior Permanent Magnet Motor Drives for Field-Weakening Applications," Ph.D. dissertation, Dept. Elec. Elect. Eng., Univ. Glasgow, Glasgow, U.K., 1993.

[6] T. M. Jahns, "Torque production in permanent magnet synchronous motor drives with rectangular current excitation," IEEE Trans. Ind. Applicat., vol. 20, pp. 803-813, July-Aug. 1984.

[7] C. S. Cambier et al., "Brushless dc Motor Using Phase Timing Advancement,", Oct. 14, 1997.

[8] J. S. Lawler, J. M. Bailey, J. W. McKeever, and J. Pinto, "Limitations of the conventional phase advance method for constant power operation of the brushless dc motor," in Proc. IEEE Southeast Conf, Apr. 5-7, 2002, pp. 174-180.

[9] J. S. Lawler, J. M. Bailey, and J. W. McKeever, Extended constant power speed range of the brushless DC motor through dual mode inverter control, , Oak Ridge National Lab., UT-Battelle, LLC, 2001.

[10] J. M. Bailey et al., Dual mode inverter control test verification, in , Oak Ridge National Lab., UT-Battelle, LLC, ORNL/TM-2000/172, 2001.

[11] J. A. Melkebeek, "Stability analysis of induction motors with SCR voltage control," in Proc. 18th UPEC, Guildford, U.K., 1983, pp. 2C1/1-2C1/6.

[12] F. M. Khater and D. W. Novotny, "An equivalent circuit model for phaseback voltage control of AC machines," IEEE Trans. Ind. Applicat., vol. 22, pp. 835-841, July-Aug. 1986.

[13] D. W. Novotny and T. King, "Equivalent circuit representation of current inverter driven synchronous machines," IEEE Trans. Pattern Anal. Machine Intell., vol. 100, pp. 2920-2926, June 1981. 